Article

\title{
The Electrical, Mechanical and Surface Properties of Thermoplastic Polyester Elastomer Modified by Electron Beta Radiation
}

\author{
David Manas ${ }^{1,2, \dagger}$, Ales Mizera ${ }^{1, *}\left(\mathbb{D}\right.$, Milan Navratil ${ }^{1}$, Miroslav Manas ${ }^{1}$, Martin Ovsik ${ }^{2} \mathbb{C}$, \\ Stanislav Sehnalek ${ }^{1}\left[\right.$ and Pavel Stoklasek ${ }^{1}$ \\ 1 Faculty of Applied Informatics, Tomas Bata University in Zlin, CEBIA-Tech, Nad Stranemi 4511, \\ 76005 Zlin, Czech Republic; manas@utb.cz (D.M.); navratil@utb.cz (M.N.); manas@fai.utb.cz (M.M.); \\ sehnalek@fai.utb.cz (S.S.); pstoklasek@utb.cz (P.S.) \\ 2 Faculty of Technology, Tomas Bata University in Zlin, Vavreckova 275, 76001 Zlin, Czech Republic; \\ ovsik@utb.cz \\ * Correspondence: mizera@utb.cz; Tel.: +420-576-035-636 \\ $\dagger$ This article is dedicated, in memoriam, to David Manas.
}

Received: 3 August 2018; Accepted: 20 September 2018; Published: 22 September 2018

\begin{abstract}
The main advantages of Thermoplastic Polyester Elastomers (TPE-E) are their elastomer properties as well as their ability to be processed in the same way as thermoplastic polymers (e.g., injection moulding, compression moulding and extrusion). However, TPE-Es' properties, mainly their mechanical properties and thermal characteristics, are not as good as those of elastomers. Because of this TPE-Es are often modified with the aim of improving their properties and extending their range of application. Radiation cross-linking using accelerated electron beams is one of the most effective ways to change virgin polymers' properties significantly. Their electrical (that is to say permittivity and resistivity measurements), mechanical (that is, tensile and impact tensile tests), as well as surface (that is, nano-indentation) properties were measured on modified/cross-linked TPE-E specimens with and/or without a cross-linking agent at irradiation doses of 0, 33, 66, 99, 132, 165 and $198 \mathrm{kGy}$. The data acquired from these procedures show significant changes in the measured properties. The results of this study allow the possibility of determining the proper processing parameters and irradiation doses for the production of TPE-E products which leads to the enlargement of their application in practice.
\end{abstract}

Keywords: thermoplastic polyester elastomer; irradiation; radiation cross-linking; electrical and mechanical properties

\section{Introduction}

TPE-E is a member of a relatively new group of thermoplastic elastomers whose production grows year on year, mainly due to their price and excellent properties. They are often used as a substitute for classic elastomers. However, the TPE-E properties do not attain the levels of elastomer properties over the entire temperature range, which leads to some limitations. Because of this granulate manufacturers prepare TPE-E with precise properties for the needs of the automotive and electrical industries [1,2]. It is a block copolymer which typically consists of hard segments composed of several short chain esters, (e.g., tetramethylene terephthalate), and soft parts containing aliphatic polyether and polyester glycol [3]. Nagai et al., at the end of the 1990s, studied the influence of weather on TPE-E and evaluated the impact of photo-degradation, thermal degradation and hydrolysis on this material. As with other thermoplastic elastomers the hard-crystalline domains of TPE-E ensure elastomer properties and heat resistance while soft amorphous ones have good low-temperature flexibility $[4,5]$. 
Several possibilities exist regarding ways to improve mechanical and electrical properties; in particular temperature stability for example, by using inorganic particles (which is a common practice). Nowadays, micro-sized or nano-sized particles, (e.g., clay, talc mica, silica, fly ash, carbon nanotubes, etc.), are used as filler that improves certain TPE-E properties [6-12]. The resulting properties depend on the filler used and its concentration and shape can provide better cohesion between the matrix and the filler. The larger the specific surface area of the filler the greater the cohesion with the matrix. Similarly, the particle size and dispersity of the TPE-E particles are manifested in the resulting properties $[13,14]$. Dielectric properties can be improved by adding nanoclay, on the other hand the conductivity can be improved by adding a metallic filler. The amount of filler is limited by the workability of the resulting mixture where the optimal ratio between the filler and the matrix has to be found so that the utility properties and the economics of the process are optimal [15-17].

Other possibilities for improving TPE-E properties and temperature stability especially for instance, can be the use of radiation cross-linking using electron beta rays. This can effectively be used to modify certain properties according to specific requirements. This type of modification has been widely known for a long time now and is widely used in the manufacturing of cables and hoses. Some polymers can be cross-linked without the help of cross-linking agents, (e.g., TPE-E, LDPE, and HDPE); others need a cross-linking agent, (e.g., polyamides and polypropylenes), without which this predominantly leads to degradation. A cross-linking agent can also be used for thermoplastics that are mainly cross-linked. It is mainly used to reduce the irradiation dose and to accelerate the cross-linking process. Cross-linked thermoplastics lose the ability to re-melt which greatly deteriorates the possibilities of their processing after the end of their life cycle or the processing of production waste [18-22].

Many studies deal with the measurement and evaluation of the mechanical properties of variously modified TPE-E; however, the measurement of their electrical properties is an area which has yet to be fully explored, and especially, about radiated cross-linked TPE-E [23-26]. Our previous study compared the mechanical properties of TPE-E, with, and without, a cross-linking agent. It was determined that for mechanical properties the addition of a cross-linking agent at low doses, (up to $66 \mathrm{kGy}$ ) does not affect it. On the other hand, at higher doses (up to $198 \mathrm{kGy}$ ) the effect of the cross-linking agent on the mechanical behaviour of TPE-E was significant [27].

The main aim of this study is to obtain as much information about the possibilities of exploiting cross-linking agents in the TPE-E structure in comparison to a material without cross-linking agents for the TPE-E behaviour at different irradiation doses. The acquired information from electrical and mechanical measurements including the surface properties of the TPE-E material being studied, leads to a comprehensive set of knowledge/information that will provide not only scientists but polymer materials manufacturers and associated engineers with lots of room for further improvements/extensions of TPE-E application possibilities.

\section{Materials and Methods}

\subsection{Materials}

A thermoplastic polyester elastomer (Teknor Apex, Pawtucket, RI, USA) without (TPE-E, PTS-UNIFLEX-E25D/M*M800 natural) and with (V-TPE-E, V-PTS-UNIFLEX-E25D/M*M800/20 natural) a cross-linking agent was used as the basic polymer materials. After the radiation cross-linking by beta-electron rays, these materials change the structure from the thermoplastic material to not re-meltable one. For easier orientation in the text, the cross-linked TPE-E and V-TPE-E are marked TPE-Ex and V-TPE-Ex, respectively.

\subsection{Specimen Preparation}

An ARBURG Allrounder 170U 150-30 injection moulding machine (Arburg, Loßburg, Germany) was used for specimen preparation, with the processing conditions to comply with the TPE-E and 
V-TPE-E producer's recommendations (Table 1). For all mechanical measurements, the samples of 1BA type produced according to ISO 527-2 standard [28] were used. The dimensions and shape of test specimens are apparent from Figure 1.

Table 1. Injection moulding parameters.

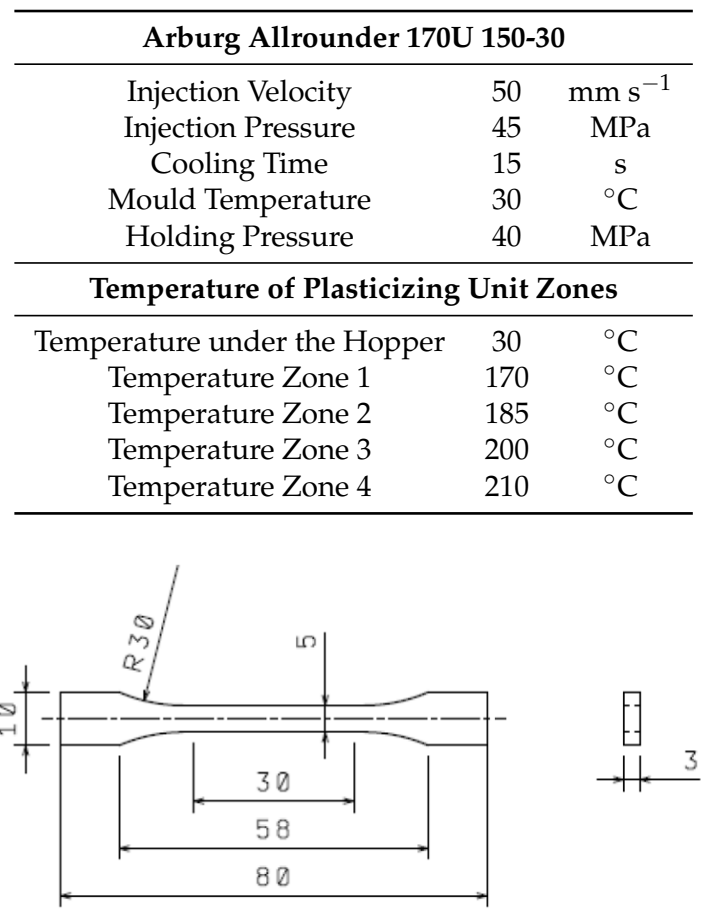

Figure 1. Dimensions of testing specimen.

$100 \times 100 \times 0.3 \mathrm{~mm}$ sheets were used to measure the electrical properties. They were produced by the compression moulding method, at a temperature of $200^{\circ} \mathrm{C}$, and a pressure of $5 \mathrm{MPa}$. The thickness of the film was measured with a micrometre, in 15 locations and ranged within a tolerance range of $\pm 0.02 \mathrm{~mm}$, which is appropriate for accurate measurements and their subsequent evaluation of resistivity and permittivity.

Irradiation of tested TPE-E and V-TPE-E was performed with the kind help of BGS Germany, in the BGS Wiehl plant using accelerated electrons. For these purposes, RHODOTRON E-beam accelerator (IBA, Tongeren, Belgium) with an energy of electrons $10 \mathrm{MeV}$ was used. Irradiation process of TPE-E and V-TPE-E specimens carried out at general conditions (air atmosphere, ambient temperature $23^{\circ} \mathrm{C}$ ) as it is performed in engineering practice. The range of the doses was determined by the experience from the practice of the industrial irradiation in the range from 33 to $198 \mathrm{kGy}$. Each passage under the accelerator scanner is equal to $33 \mathrm{kGy}$. The required dose was determined according to accelerator parameters, and its correctness was measured by the dosimeter. Nylon FWT 60-00 dosimeter (Far West Technology, Inc., Goleta, CA, USA) was used to check the correct radiation dose, following analysis was carried out on spectrophotometer Genesis 5, according to the ASTM 51261 standard [29]. Required and real surface value of gain irradiation dose is described in Table 2. 
Table 2. Irradiation dose of TPE-E and V-TPE-E.

\begin{tabular}{cc}
\hline Required Irradiation Dose (kGy) & Real Surface Irradiation Dose (kGy) \\
\hline 0 & 0.0 \\
33 & 38.7 \\
66 & 77.4 \\
99 & 116.1 \\
132 & 154.8 \\
165 & 193.5 \\
198 & 232.2 \\
\hline
\end{tabular}

\subsection{Gel Content}

Gel test is done to find the content of non-dissolved phase-gel of the given material according to standard ASTM D 2765-test method C [30]. The portion of $0.5 \mathrm{~g}$ (of the electron beam irradiated TPE-Ex and V-TPE-Ex material) weighed with a precision of five decimal places on weighing apparatus "SWISS MADE EP 125 SM" was mixed with $100 \mathrm{~mL}$ of solvent. Xylene was used for TPE-Ex and V-TPE-Ex because it dissolves, on the other hand the cross-linking part does not dissolve. The mixture was extracted for $24 \mathrm{~h}$. Then solutes were separated by distillation. After removing the residual xylene, the cross-linked extract was dried for eight hours in vacuum at $100{ }^{\circ} \mathrm{C}$. The dried and cooled residue was weighed again with precision to five decimal places and compared to the original weight of the portion. The result is stated in percentage as the degree of cross-linking.

$$
G_{i}=\frac{m_{3}-m_{1}}{m_{2}-m_{1}} 100
$$

where $G_{i}$ is the degree of cross-linking of each specimen expressed in percentage, $m_{1}$ is the weight of the cage and lid in milligrams, $m_{2}$ is the total of weights of the original specimen, cage and lid in milligrams, and $m_{3}$ is the total of the weights of the residue of specimen, cage and lid in milligrams.

\subsection{Volume Resistivity Measurement}

Volume resistivity $\rho_{v}$ is defined as the electrical resistance through a cube of insulating material. The standard resistivity test method for an insulator involves applying a voltage step using voltage source, for a specified period. In our case, the voltage-current force measurement technique is used. The measuring system consists of a precise electrometer a Keithley 6517A with an 8009 resistivity test fixture. The sample is positioned between the electrodes and a voltage of $500 \mathrm{~V}$ is applied. The time dependence of the resultant current is measured for 60 seconds, due to polarising procedures; after this period the current flow is sufficiently stabilised. The sample resistance and volume resistivity are calculated according to Ohm's Law and the geometrical considerations of electrodes used, as follows:

$$
\rho_{v}=\frac{A}{t} \frac{U}{I}
$$

where $\rho_{v}$ is volume resistivity $[\Omega \mathrm{m}] ; A$ is the effective area of the guarded electrode for the particular electrode for the arrangement employed $\left[\mathrm{m}^{2}\right] ; t$ is the sample thickness $[\mathrm{m}] ; R$ is the calculated resistance $[\Omega] ; U$ is voltage $[\mathrm{V}]$; and I is current $[\mathrm{A}]$.

The above-mentioned test procedure conforms to ASTM D-257 [31] and IEC 62631-3-1 [32] Standards for DC Resistance of Insulating Materials.

\subsection{Permittivity Measurement}

Loss factor $\tan (\delta)$ and relative permittivity $\epsilon_{R}$ are two important material parameters that enable one to evaluate substances (insulators), which are evaluated among themselves. Based on these parameters, it is possible to determine the exact application of the materials used. The loss factor characterises insulators in dielectric loss terms. Relative permittivity corresponds to electrostatic forces in materials and is defined as the permittivity of a given material, relative to the permittivity of a 
vacuum. The parallel-plate capacitor method was chosen for this measurement procedure. It involves sandwiching a thin sheet of material between two electrodes, to form a capacitor. The measuring system consists of a Keysight E4980A precision LCR meter, and the HP 16451B dielectric test fixture. After initial calibration the capacitance value, along with a parallel-equivalent circuit model and the loss factor of the material, is measured at frequency ranges from $20 \mathrm{~Hz}$ to $1 \mathrm{kHz}$. The values obtained, and the geometrical considerations of the electrodes used, as well as relative permittivity are calculated as follows:

$$
\varepsilon_{R}(\omega)=\frac{t C_{p}(\omega)}{\varepsilon_{0} A}
$$

where $\omega$ is angular frequency [rad s$\left.~ s^{-1}\right]$; $t$ is the thickness of the sample $[\mathrm{m}] ; \mathrm{Cp}$ is the capacitance value $[\mathrm{F}], \varepsilon_{0}$ is the permittivity of the vacuum $\left[\mathrm{Fm}^{-1}\right]$; and $A$ is the effective area of the guarded electrode $\left[\mathrm{m}^{2}\right]$. The dielectric properties' results presented herein are given for $1 \mathrm{kHz}$ frequency since it is usually provided in technical standards.

\subsection{Tensile Test}

The tensile test was carried out on a T 2000 Alpha Technologies testing machine at ambient temperature $23{ }^{\circ} \mathrm{C}$ according to ISO 37 standard [33], under a constant speed of elongation of $500 \mathrm{~mm} \mathrm{~min}^{-1}$. The used testing samples were in the shape of a shovel as displayed in Figure 1. 15 samples were tested, and their ultimate tensile strength and elongation at break values were evaluated in TestExpert II, MS Excel and MiniTab programs. In all figures arithmetic mean and standard deviation are used.

\subsection{Impact Tensile Test}

The tensile impact test was carried out on Zwick HIT50P equipment (Zwick, Ulm, Germany) at ambient temperature of $23{ }^{\circ} \mathrm{C}$ according to standard ISO 8256 [34]. $50 \mathrm{~J}$ impact hammer was used on this test. 15 specimens (Figure 1) were tested, and their ultimate impact tensile strength values were evaluated in TestExpert II, MS Excel and MiniTab programs. Arithmetic mean and standard deviation were used as the statistical parameters in this measurement.

\subsection{Nano-Indentation Test}

Nano-indentation test was performed using a nano-indentation tester (nano hardness tester), Anton Paar (Graz, Austria) according to the ISO 14577 standard [35]. The Depth-Sensing Indentation (DSI) method used enables measuring of the force acting on the Vickers indentor (Anton Paar, Graz, Austria) which is made of diamond, the shape of a cube corner and the displacement of the indentor during the test. In the present study, the maximum load used was $0.1 \mathrm{~N}$ and loading and unloading rate was $0.2 \mathrm{~N} \mathrm{~min}^{-1}$, while the holding time was $90 \mathrm{~s}$.

Measurements of all properties mentioned above were performed 30 times to ensure statistical correctness.

\section{Results and Discussion}

\subsection{Gel Content Determination}

Table 3 shows the gel content values as measured using the xylene extraction method, according to ASTM D 2765, test method C [30]. At the lowest irradiation dose of $33 \mathrm{kGy}$ no gel content was measured for both types of TPE-Ex and V-TPE-Ex by this method. As with irradiated TPE-Ex with a dose of $66 \mathrm{kGy}$ the gel content was not measured; the possible cause may be the formation of micro-gels that were not entrapped by the screen during extraction. On the other hand, the gel content of V-TPE-Ex increased by $78 \%$ at this dose. For TPE-Ex a gel content of $57 \%$ was measured at a dose of $99 \mathrm{kGy}$. With increasing doses of radiation the gel content of the both tested TPE-Ex and V-TPE-Ex 
gradually increased. At the maximum irradiation dose of $198 \mathrm{kGy}$ the gel content difference between TPE-Ex and V-TPE-Ex is 19\%. From the measured values it can be concluded that the presence of a cross-linking agent in the TPE-E structure has a significant effect on the reduction of the radiation dose, which allows for greater production results and reductions in production costs.

Table 3. Gel Content.

\begin{tabular}{cccccccc}
\hline Radiation Dose & 0 kGy & 33 kGy & 66 kGy & 99 kGy & 132 kGy & 165 kGy & 198 kGy \\
\hline TPE-E & $0 \%$ & $0 \%$ & $0 \%$ & $57 \%$ & $69 \%$ & $69 \%$ & $74 \%$ \\
V-TPE-E & $0 \%$ & $0 \%$ & $78 \%$ & $79 \%$ & $87 \%$ & $92 \%$ & $93 \%$ \\
\hline
\end{tabular}

\subsection{Volume Resistivity Measurement}

The first quantity measured was volume resistivity which serves as an indicator of the electric properties; the higher this is the better the insulation properties of the material. Since TPE-E belongs to a group of materials with excellent electric properties a large change in these properties is not expected, due to the addition of a cross-linking agent and subsequent cross-linking with beta-electron radiation.

As can be seen in Figure 2 the volume resistivity measured over the period of sixty seconds seems primarily to increase exponentially and then the value becomes reliably stable. For comparison purposes the electrification time of $60 \mathrm{~s}$ was chosen, with an applied voltage of $500 \mathrm{~V}$.

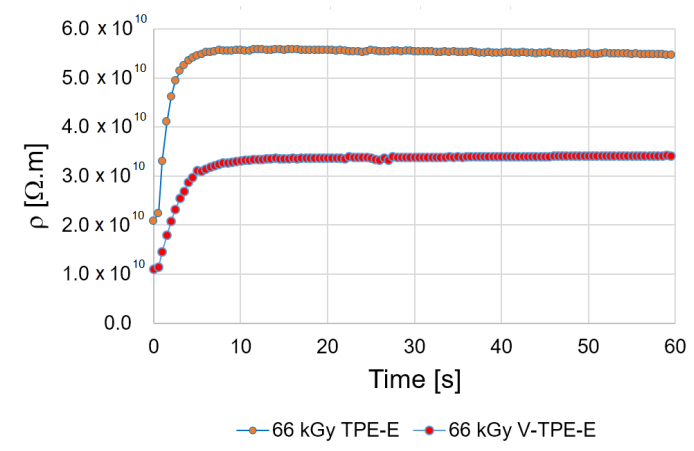

Figure 2. Measurement course of the volume resistivity at voltage of $500 \mathrm{~V}$.

The value of the volume resistivity values was measured in the order of dozens of $G \Omega$; while the measurement error proved relatively small as shown in Figure 3. However, it can be observed from the measured values that radiation cross-linking does not impair the electric properties; on the contrary; there is a slight improvement. For V-TPE-Ex there was a slight decrease in volume resistivity than for TPE-Ex except for the irradiation dose of $132 \mathrm{kGy}$, despite this drop in values being higher than virgin TPE-E.

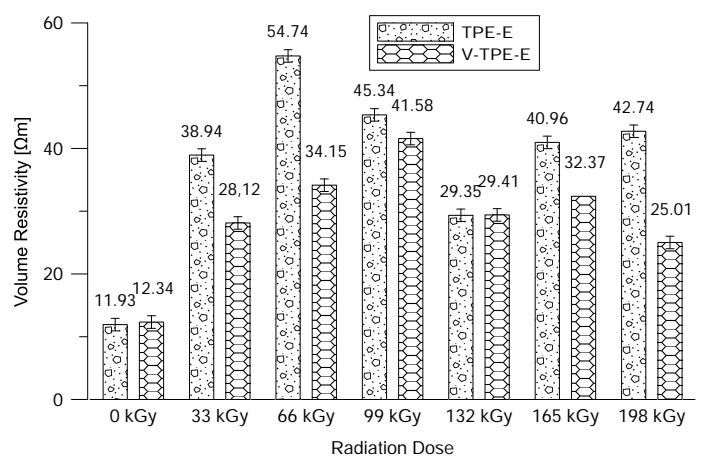

Figure 3. Volume resistivity at voltage of $500 \mathrm{~V}$ after $60 \mathrm{~s}$. 


\subsection{Permittivity Measurement}

Further measurements of the electrical parameters included the relative permittivity and the loss factor, which also served for the evaluation of the insulation characteristics of the materials. Concerning the fact that TPE-E is non-polar dielectric both relative permittivity and the loss factor are not dependent on frequency or temperature. Figures 4 and 5 show the frequency dependence of relative permittivity which is almost constant except for at lower frequencies. This is caused due to uncertainties relating to the measurement method for the lowest frequency range. The radiation dose does not affect the relative permittivity of TPE-Ex; however, with V-TPE-Ex the radiation dose increased to $66 \mathrm{kGy}$ and led to a slight decrease and with a further increase in the radiation dose, there was a gradual increase of up to $165 \mathrm{kGy}$, where the relative permittivity value stabilised at roughly about 4 . It can also be observed from the relative permeability measurements that TPE-E irradiation did not result in any radical deterioration of the dielectric properties (Figure 6).

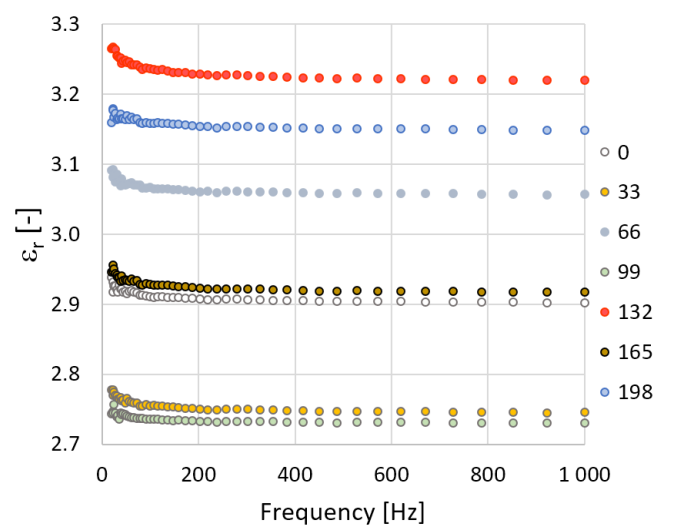

Figure 4. TPE-E-measurement course of the relative permittivity in dependence on frequency.

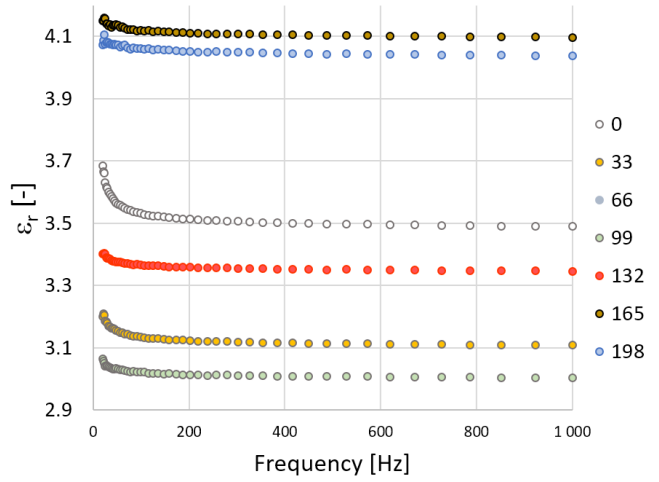

Figure 5. V-TPE-E-measurement course of the relative permittivity in dependence on frequency.

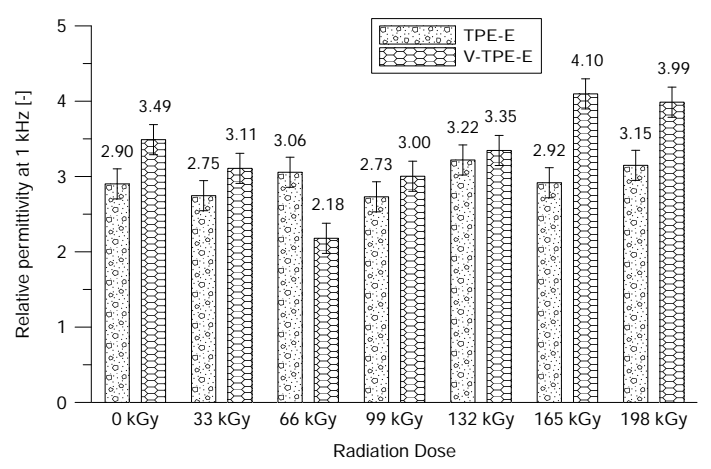

Figure 6. Relative permittivity measured at $1 \mathrm{kHz}$. 
In Figures 7 and 8 it can be seen that the loss factor decreases exponentially over the frequency. The loss factor decreases in line with higher irradiation doses. This also means there are decreases in electric conductivity values. The addition of cross-linking agents to the V-TPE-E led to the growth of the loss factor value by 0.001 , within the overall range of the radiation doses. This may mean slightly greater heating of the material in comparison to TPE-E under the influence of the through-flow of the electric current (Figure 9).

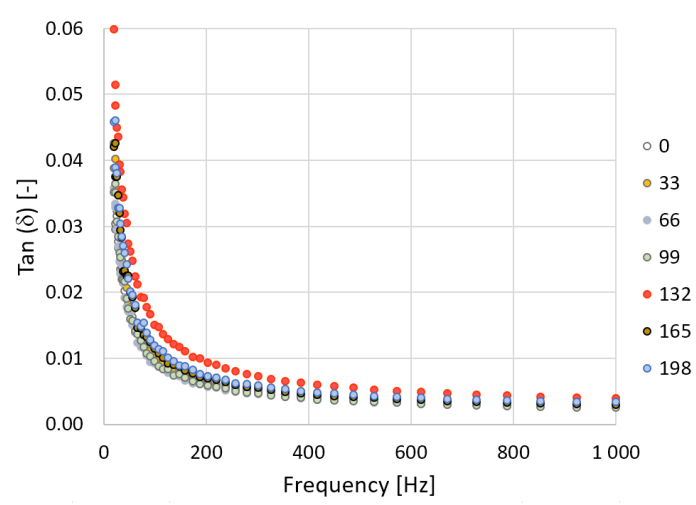

Figure 7. TPE-E—measurement course of the loss factor in dependence on frequency.

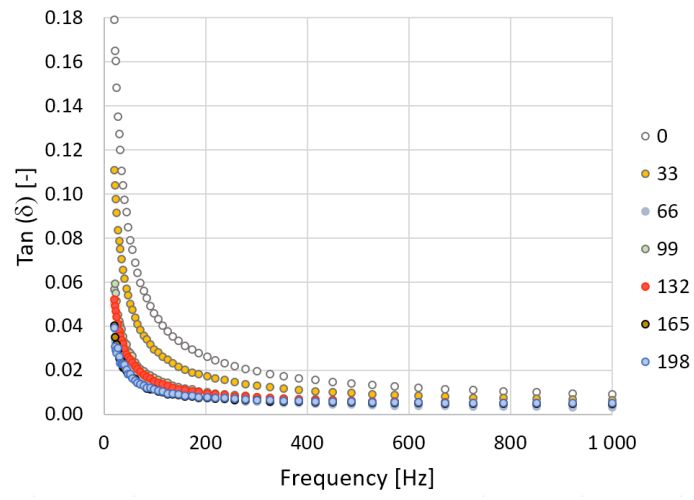

Figure 8. V-TPE-E-measurement course of the loss factor in dependence on frequency.

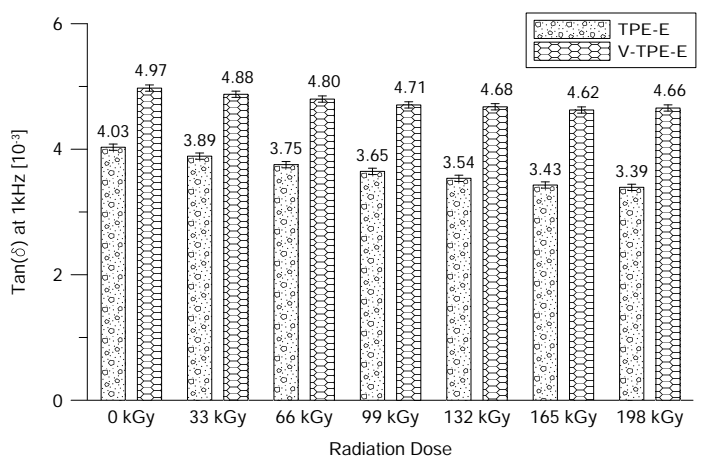

Figure 9. Loss factor measured at $1 \mathrm{kHz}$.

\subsection{Tensile Tests}

Following the electrical properties' tests further tests were made on the mechanical properties and in particular the static and impact tensile properties were measured. Regarding the static tensile properties, the ultimate tensile strength and elongation at break were evaluated. In case of the impact tensile properties the ultimate impact tensile strength was evaluated; elongation at break was not measured due to overloading the test specimens with a hammer energy of $50 \mathrm{~J}$. 
The ultimate tensile strength increases gradually at low radiation doses (up to $66 \mathrm{kGy}$ ) while the effect of the cross-linking agent is minimal. With an increasing radiation dose (up to $198 \mathrm{kGy}$ ) the ultimate tensile strength drops. V-TPE-Ex at $198 \mathrm{kGy}$ is about 4.6 MPa lower than the value of TPE-Ex at the same radiation dose (Figure 10). Decreases in ultimate tensile strength indicate the gradual degradation of the material due to the amount of radiation. From this point-of-view the optimal dose would appear to be between 66 and $99 \mathrm{kGy}$ where the highest ultimate tensile strength was measured and correlated with gel content measurements showing the jump increase in gel content that was measured at these doses.

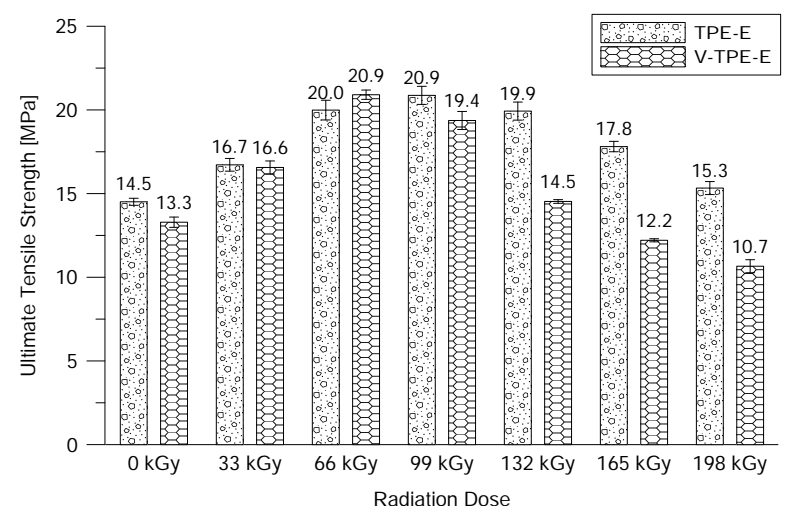

Figure 10. Ultimate tensile strength dependence on the radiation dose.

Figure 11 depicts the dependence of elongation at the break on the radiation dose. Based on this measurement process it can be observed that cross-linking agents in V-TPE-E worsen elongation. Only by the fact of their being present; the ensuing radiation cross-linking is the value of elongation at break and is constant in samples up to a radiation dose of $66 \mathrm{kGy}$; this then drops sharply to $259.3 \%$ at a dose of $198 \mathrm{kGy}$. A similar pattern is also observed for TPE-E; nevertheless, the elongation at break value is, at $198 \mathrm{kGy}$, more than double that of V-TPE-Ex. At a dose of $66 \mathrm{kGy}$ the difference in elongation at break between TPE-Ex and V-TPE-Ex is 139.1\%. The decline in elongation at break increases with radiation doses. This is probably caused on the one hand, by the "cramping" of the cross-linking networks with the "stiffness" of cross-linking; which is no longer as resilient as virgin TPE-E. On the other hand high doses lead to the degradation which also could contribute to elongation changes.

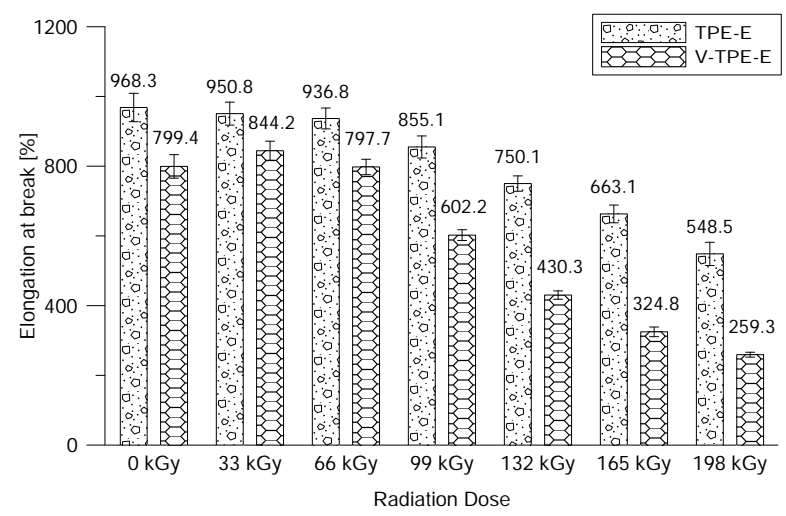

Figure 11. Elongation at break dependence on the radiation dose.

Figure 12 shows the dependence of the maximum impact tensile strength on the radiation dose. Unlike the tensile properties measured under static load, the impact load led to the opposite trend, with the ultimate impact tensile strength gradually increasing to a maximum irradiance of $198 \mathrm{kGy}$. The material does not have time to adapt to the applied load and thus fails to capture changes taking place in the material sensitively enough. However, it can be noted that the addition of a cross-linking agent does not worsen the tensile properties at impact loads even at higher radiation doses; on the 
contrary, the ultimate impact tensile strength increased by 7.74 MPa for V-TPE-Ex at $198 \mathrm{kGy}$ as compared to V-TPE-E that was not irradiated. Here, the curves correlate very well with the gel content measurements.

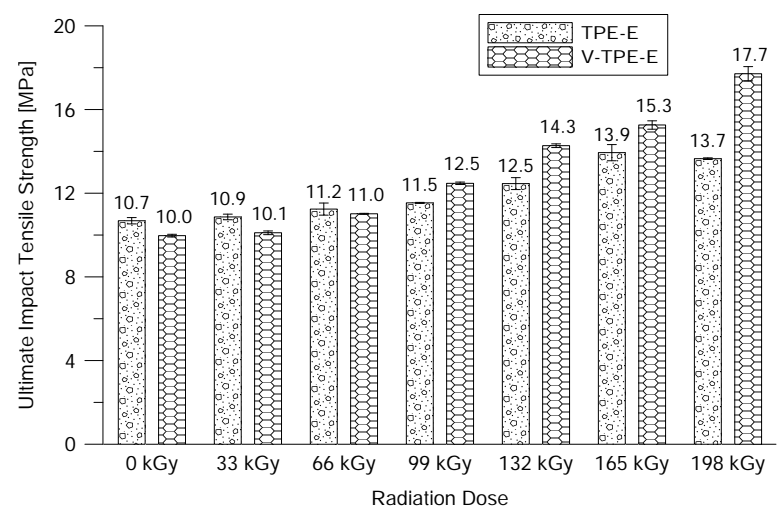

Figure 12. Ultimate impact tensile strength dependence on the radiation dose.

\subsection{Nano-Indentation Test}

The surface properties were evaluated using DSI-to be more precise the nano-indentation properties (i.e., indentation hardness, indentation modulus, elastic deformation work and plastic deformation work) after exposure to beta-electron radiation.

From Figure 13 it is apparent that the indentation hardness of V-TPE-Ex lies to the full extent within the range of radiation doses (except of the dose of $33 \mathrm{kGy}$ ) used in the measurement error area where the indentation hardness is around $54 \mathrm{MPa}$ and it is in all cases oscilating around the value of indentation hardness of non-irradiated V-TPE-E. On the other hand TPE-Ex showed an increase in indentation hardness in the radiation dose ranging from 33 to $132 \mathrm{kGy}$ with the maximum at the dose of irradiation of $132 \mathrm{kGy}$. This value is about $196 \%$ higher than that of virgin TPE-E. Increases may have been influenced by the cross-linking of the surface layer; with further increases in radiation dose the indentation hardness dropped to the original virgin TPE-E value which could have caused the subsequent degradation of the surface layer.

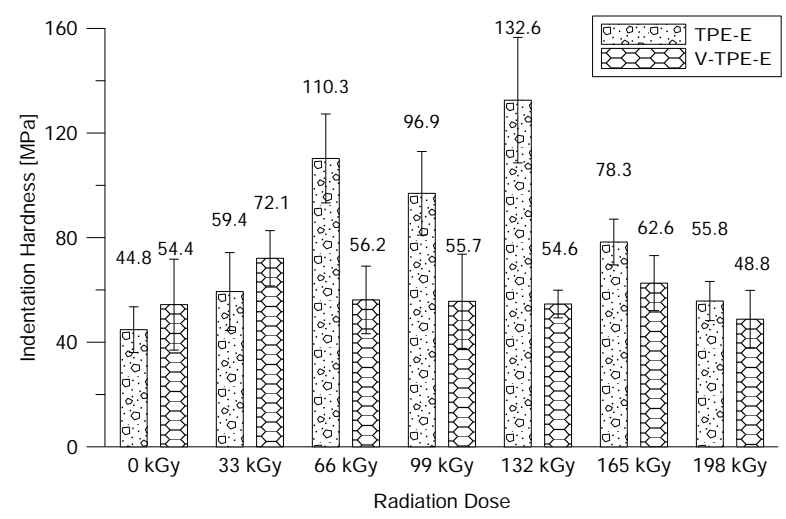

Figure 13. Nano-indentation hardness dependence on the radiation dose.

A similar tendency can be observed for the nano-indentation modulus results. The nano-indentation module V-TPE-Ex results fluctuate within the framework of measurement errors around $160 \mathrm{MPa}$ in the whole range of the radiation dose. As regards TPE-Ex there is a significant growth in the measured values with its maximum attained with a radiation dose of $132 \mathrm{kGy}$ and with the subsequent decrease in value to almost that of non-irradiated TPE-E (see Figure 14). 


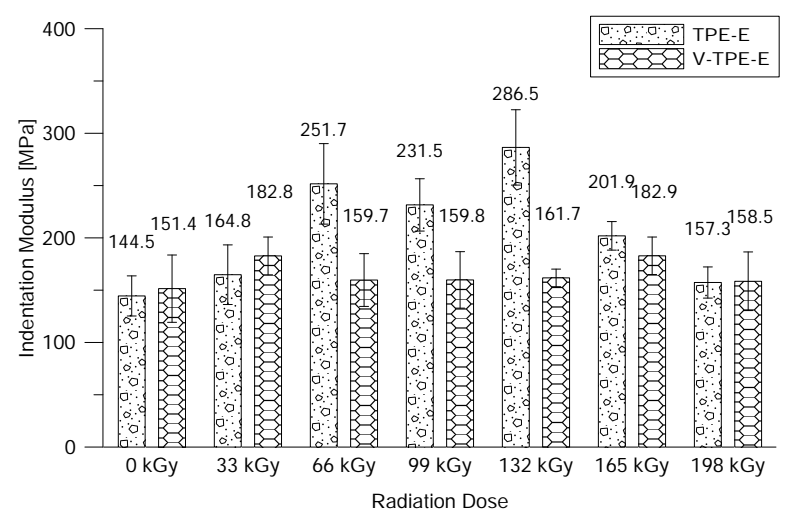

Figure 14. Nano-indentation modulus dependence on the radiation dose.

A similar tendency as when measuring the nano-indentation hardness and the modulus demonstrates the elastic and plastic deformation work (see Figures 15 and 16).

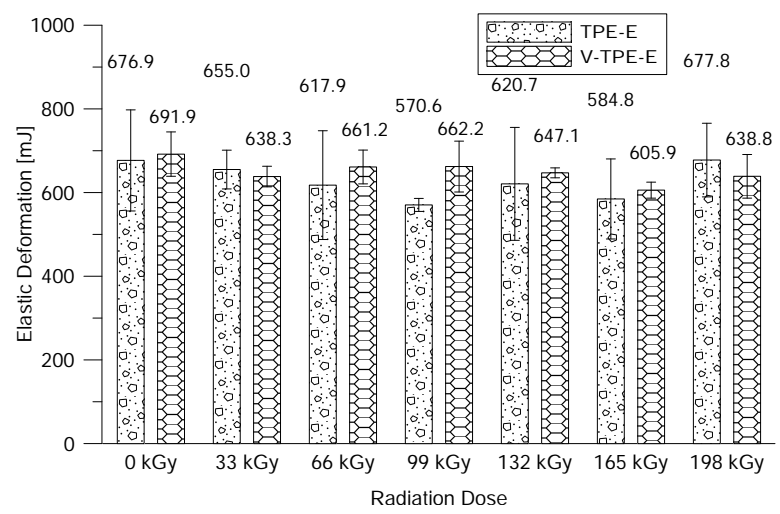

Figure 15. Elastic indentation work dependence on the radiation dose.

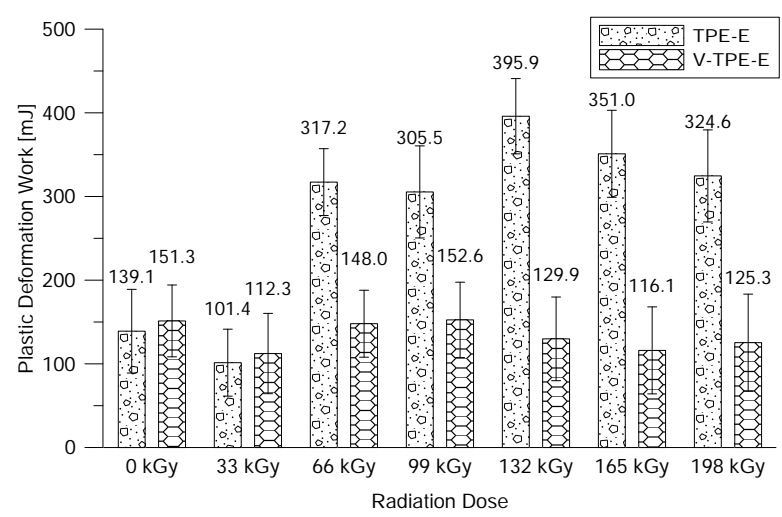

Figure 16. Plastic indentation work dependence on the radiation dose.

\section{Conclusions}

Thermoplastic polyester elastomers are widely used due to their workability just like for thermoplastics, (injection moulding, extrusion, etc.), while they do achieve the properties of elastomers. The greatest limiting factor for TPE-E is its lower service temperature in comparison with elastomers. However, there are certain ways of modification, such as radiation cross-linking, which lead to increases of temperature stability [27,36]. TPE-E is generally a cross-linked material, (it does not require a cross-linking agent for cross-linking purposes); nevertheless, a $5 \%$ cross-linking agent is generally added, which ensures a faster reaction and maintains the stability of the cross-linking 
process. The choice of input material (with or without a cross-linking agent), depends on the resultant properties of radiation cross-linked TPE-Ex products.

From the gel content measurements, it is evident that V-TPE-Ex is cross-linked faster (at $66 \mathrm{kGy}$ ) than TPE-Ex (99 kGy). Similarly, the gel content of V-TPE-Ex at the maximum radiation dose (198 kGy) is much higher $(93 \%)$, than for TPE-Ex $(74 \%)$. Based on this measurement, the minimum radiation dose that is suitable for the radiation cross-linking of TPE-E can be determined. However, the specified minimum dose of radiation need not have the best results for electrical, mechanical and surface properties. It is necessary to optimise the radiation dose according to the final use of the product.

Based on electrical properties-volume resistivity, relative permittivity and loss factor, it was ascertained that radiation cross-linking does not worsen these properties, but on the contrary, certain radiation doses improve electrical properties. The addition of a cross-linking agent to V-TPE-E causes an increase in loss factor by 0.001 over the full range of radiation doses, which can cause slightly higher heating of the electric current than for TPE-E.

The tensile properties correlate with the gel content measurements while the optimal dose for V-TPE-Ex is $66 \mathrm{kGy}$, and for TPE-Ex is $99 \mathrm{kGy}$. These measured values indicate that, by adding a cross-linking agent a radiation dose reduction of 99 to $66 \mathrm{kGy}$ could be achieved with the similar mechanical properties.

The last measurement in this study was the measurement of surface properties by using the nano-indentation method. This relates to the measurement of the hardness of the surface layer ranging from several units and up to tens of micrometres. This method can be used to evaluate the indentation hardness and modulus, the elastic and the plastic deformation work. With V-TPE-E, the cross-linking agent did not lead to changes in the surface properties throughout the whole range of radiation doses. On the other hand, TPE-Ex ranged from 66 and $132 \mathrm{kGy}$ led to increases in indentation hardness and modulus.

Addition of a cross-linking agent to TPE-E does not lead to the impairment of the properties studied; in certain cases, improvements occurred. When is using a cross-linking agent the radiation dose can be reduced to $66 \mathrm{kGy}$ which results in a certain reduction in production costs.

Author Contributions: D.M., P.S., M.O. designed and performed the experiments; M.N. and S.S. analysed the data; M.M. and A.M. conceived and designed the experiments and wrote the paper.

Funding: This research received no external funding.

Acknowledgments: Our great thanks belong to our colleague and co-worker, David Manas, for his long lasting cooperation and supervision of numerous academic diploma works and theses. David was a promising-and highly regarded pedagogue and scientist; and a leading person in the research area presented in this article. He passed away unexpectedly in mid-September 2017, at the age of only 42. We were honoured to work with him. May his soul rest in peace. The authors of this article would especially like to thank the firm-BGS, Germany, and Michal Danek especially, for their kind assistance in the realisation of radial cross-linking. This work was supported by the European Regional Development Fund under the project CEBIA-Tech Instrumentation No. CZ.1.05/2.1.00/19.0376 and by the Ministry of Education, Youth and Sports of the Czech Republic within the National Sustainability Programme project No. LO1303 (MSMT-7778/2014).

Conflicts of Interest: The authors declare no conflict of interest.

\section{References}

1. Kricheldorf, H. Thermoplastic Elastomers; Hanser Gardner Publications: Cincinnati, OH, USA, 2004.

2. Spontak, R.J.; Patel, N.P. Thermoplastic elastomers: fundamentals and applications. Curr. Opin. Colloid Interface Sci. 2000, 5, 333-340. [CrossRef]

3. Drobny, J. Handbook of Thermoplastic Elastomers; William Andrew Publisher: Norwich, NY, USA, 2014.

4. Nagai, Y.; Ogawa, T.; Zhen, L.Y.; Nishimoto, Y.; Ohishi, F. Analysis of weathering of thermoplastic polyester elastomers-I. Polyether-polyester elastomers. Polym. Degrad. Stab. 1997, 56, 115-121. [CrossRef]

5. Nagai, Y.; Ogawa, T.; Nishimoto, Y.; Ohishi, F. Analysis of weathering of a thermoplastic polyester elastomer II. Factors affecting weathering of a polyether-polyester elastomer. Polym. Degrad. Stab. 1999, 65, 217-224. [CrossRef] 
6. Kalfoglou, N.K. Thermomechanical studies of semicrystalline polyether-ester copolymers. Effect of thermal, mechanical, and solvent treatment. J. Appl. Polym. Sci. 1977, 21, 543-554. [CrossRef]

7. Hussain, M.; Ko, Y.H.; Choa, Y.H. Significant enhancement of mechanical and thermal properties of thermoplastic polyester elastomer by polymer blending and nanoinclusion. J. Nanomater. 2016, 2016, 69. [CrossRef]

8. Varsavas, S.D.; Kaynak, C. Effects of glass fiber reinforcement and thermoplastic elastomer blending on the mechanical performance of polylactide. Compos. Commun. 2018, 8, 24-30, doi:10.1016/j.coco.2018.03.003. [CrossRef]

9. Chen, J.; Lv, Q.; Wu, D.; Yao, X.; Wang, J.; Li, Z. Nucleation of a Thermoplastic Polyester Elastomer Controlled by Silica Nanoparticles. Ind. Eng. Chem. Res. 2016, 55, 5279-5286. [CrossRef]

10. Sreekanth, M.; Joseph, S.; Mhaske, S.; Mahanwar, P.; Bambole, V. Effects of Mica and Fly Ash Concentration on the Properties of Polyester Thermoplastic Elastomer Composites. J. Thermoplast. Compos. Mater. 2011, 24, 317-331. [CrossRef]

11. Helal, E.; David, E.; Fréchette, M.; Demarquette, N.R. Thermoplastic elastomer nanocomposites with controlled nanoparticles dispersion for HV insulation systems: Correlation between rheological, thermal, electrical and dielectric properties. Eur. Polym. J. 2017, 94, 68-86. [CrossRef]

12. Ju, S.; Zhang, H.; Chen, M.; Zhang, C.; Chen, X.; Zhang, Z. Improved electrical insulating properties of LDPE based nanocomposite: Effect of surface modification of magnesia nanoparticles. Compos. Part A Appl. Sci. Manuf. 2014, 66, 183-192. [CrossRef]

13. Qiu, Y.; Wang, J.; Wu, D.; Wang, Z.; Zhang, M.; Yao, Y.; Wei, N. Thermoplastic polyester elastomer nanocomposites filled with graphene: Mechanical and viscoelastic properties. Compos. Sci. Technol. 2016, 132, 108-115. [CrossRef]

14. Qiu, Y.; Wu, D.; Xie, W.; Wang, Z.; Peng, S. Thermoplastic polyester elastomer composites containing two types of filler particles with different dimensions: Structure design and mechanical property control. Compos. Struct. 2018, 197, 21-27. [CrossRef]

15. Helal, E.; Demarquette, N.; Amurin, L.; David, E.; Carastan, D.; Fréchette, M. Styrenic block copolymer-based nanocomposites: Implications of nanostructuration and nanofiller tailored dispersion on the dielectric properties. Polymer 2015, 64, 139-152. [CrossRef]

16. Radhakrishnan, S.; Saini, D.R. Electrical properties of polyester elastomer composites containing metallic fillers. J. Mater. Sci. 1991, 26, 5950-5956. [CrossRef]

17. Bae, J.; Lee, S.; Kim, B.C.; Cho, H.H.; Chae, D.W. Polyester-based thermoplastic elastomer/MWNT composites: Rheological, thermal, and electrical properties. Fibers Polym. 2013, 14, 729-735. [CrossRef]

18. Drobny, J. Ionizing Radiation and Polymers: Principles, Technology and Applications; William Andrew Elsevier Health Sciences Distributor: Norwich, UK, 2013.

19. Rouif, S. Radiation cross-linked polymers: Recent developments and new applications. Nucl. Instrum. Methods Phys. Res. Sect. B Beam Interact. Mater. Atoms 2005, 236, 68-72. [CrossRef]

20. Ghazali, Z.; Johnson, A.; Dahlan, K. Radiation crosslinked thermoplastics natural rubber (TPNR) foams. Radiat. Phys. Chem. 1999, 55, 73-79. [CrossRef]

21. Šarac, T.; Quiévy, N.; Gusarov, A.; Konstantinović, M. Influence of gamma-irradiation and temperature on the mechanical properties of EPDM cable insulation. Radiat. Phys. Chem. 2016, 125, 151-155. [CrossRef]

22. Boukezzi, L.; Rondot, S.; Jbara, O.; Boubakeur, A. Study of thermal aging effects on the conduction and trapping of charges in XLPE cable insulations under electron beam irradiation. Radiat. Phys. Chem. 2018, 149, 110-117. [CrossRef]

23. Lee, J.M.; Choi, B.H.; Moon, J.S.; Lee, E.S. Determination of the tear properties of thermoplastic polyester elastomers (TPEEs) using essential work of fracture (EWF) test method. Polym. Test. 2009, 28, 854-865. [CrossRef]

24. Jamaluddin, N.; Razaina, M.; Ishak, Z.M. Mechanical and Morphology Behaviours of Polybutylene (succinate)/Thermoplastic Polyurethaneblend. Procedia Chem. 2016, 19, 426-432. [CrossRef]

25. Huang, J.; Wang, J.; Qiu, Y.; Wu, D. Mechanical properties of thermoplastic polyester elastomer controlled by blending with poly(butylene terephthalate). Polym. Test. 2016, 55, 152-159. [CrossRef]

26. Huang, J.; Qiu, Y.; Wu, D.; Wang, J. New Way To Tailor Thermal Stability and Mechanical Properties of Thermoplastic Polyester Elastomer: Relations between Interfacial Structure and Surface Treatment of Spodumene Slag. Ind. Eng. Chem. Res. 2017, 56, 6239-6246. [CrossRef] 
27. Manas, D.; Mizera, A.; Manas, M.; Ovsik, M.; Hylova, L.; Sehnalek, S.; Stoklasek, P. Mechanical Properties Changes of Irradiated Thermoplastic Elastomer. Polymers 2018, 10, 87. [CrossRef]

28. International Organization for Standardization. Plastics-Determination of Tensile Properties; International Organization for Standardization: Geneva, Switzerland, 2012.

29. International Organization for Standardization. Practice for Calibration of Routine Dosimetry Systems for Radiation Processing; International Organization for Standardization: Geneva, Switzerland, 2013.

30. Standard Test Methods for Determination of Gel Content and Swell Ratio of Crosslinked Ethylene Plastics; ASTM International Standard; ASTM International: West Conshohocken, PA, USA, 2016.

31. Standard Test Methods for DC Resistance or Conductance of Insulating Materials; ASTM International Standard; ASTM International: West Conshohocken, PA, USA, 2014.

32. International Organization for Standardization. Dielectric and Resistive Properties of Solid Insulating Materials_Part 3-1: Determination of Resistive Properties (DC methods)_Volume Resistance and Volume Resistivity-General Method; International Organization for Standardization: Geneva, Switzerland, 2016.

33. International Organization for Standardization. Rubber, Vulcanized or Thermoplastic-Determination of Tensile Stress-Strain Properties; International Organization for Standardization: Geneva, Switzerland, 2017.

34. International Organization for Standardization. Plastics-Determination of Tensile-Impact Strength; International Organization for Standardization: Geneva, Switzerland, 2004.

35. International Organization for Standardization. Metallic Materials_Instrumented Indentation Test for Hardness and Materials Parameters_Part 1: Test Method; International Organization for Standardization: Geneva, Switzerland, 2015.

36. Manas, M.; Manas, D.; Stanek, M.; Mizera, A.; Ovsik, M. Modification of polymer properties by irradiation properties of thermoplastic electromer after radiation cross-linking. Asian J. Chem. 2013, 25, 5124-5128.

(C) 2018 by the authors. Licensee MDPI, Basel, Switzerland. This article is an open access article distributed under the terms and conditions of the Creative Commons Attribution (CC BY) license (http:/ / creativecommons.org/licenses/by/4.0/). 